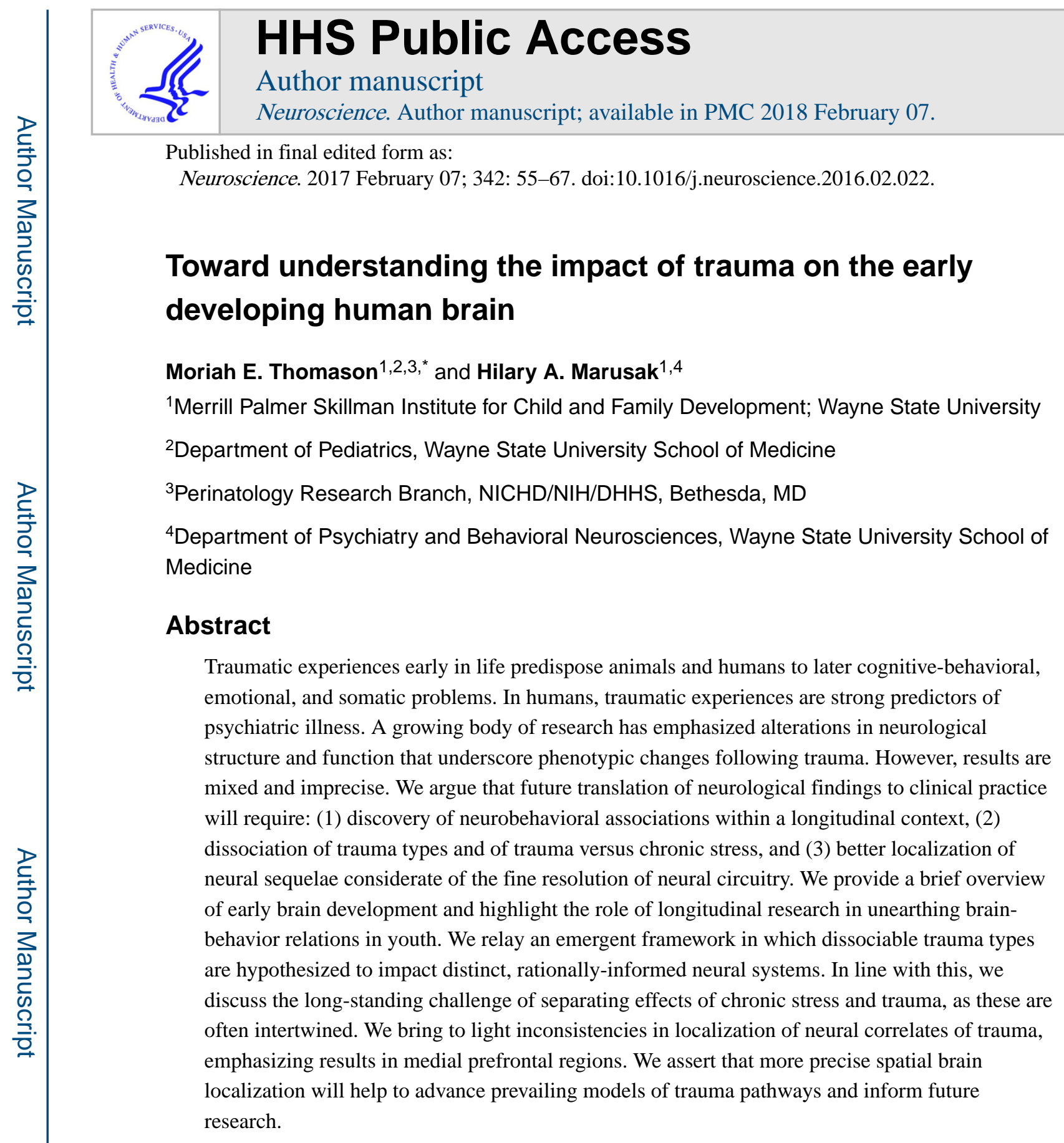

\title{
Keywords
}

Adversity; maltreatment; abuse; neural; children; adolescents

\footnotetext{
*Corresponding author: Dr. Moriah E. Thomason, Merrill Palmer Skillman Institute, Wayne State University, 71 E. Ferry Street, Detroit, MI 48009, moriah@ wayne.edu, Phone: 313-664-2517, Fax: 313-664-2555.

Publisher's Disclaimer: This is a PDF file of an unedited manuscript that has been accepted for publication. As a service to our customers we are providing this early version of the manuscript. The manuscript will undergo copyediting, typesetting, and review of the resulting proof before it is published in its final citable form. Please note that during the production process errors may be discovered which could affect the content, and all legal disclaimers that apply to the journal pertain.
} 
"And the first step...is always what matters most, particularly when we are dealing with the young and tender. This is the time when they are taking shape and when any impression we choose to make leaves a permanent mark. “

Plato, referenced in (Clarke and Clarke, 2000).

Plato's writings c. 400 BC convey fragility and malleability in the developing human brain and emphasize the significant and lasting role of early experiences. Research over the past 50 years has substantiated this long-standing view within an empirical context. Seminal studies c. 1970 in the laboratory of Harry Harlow demonstrated that early maternal separation in baby rhesus monkeys induced lasting negative behavioral effects (Young et al., 1973). Numerous investigations have followed and these converge on the idea that trauma and adverse early experiences (e.g., neglect, violence, abuse, medical trauma) leave "scars" that compromise individual wellbeing (Felitti et al., 1998, Pechtel and Pizzagalli, 2011, McEwen, 2012). The overarching goal of current research is to dissect these "scars" and to discover points of vulnerability, forms of injury, and divergent pathways of resilience or injury.

Concerns about psychopathological and neurocognitive impacts of early life trauma are widespread. The Centers for Disease Control (CDC) recognize child maltreatment as the leading preventable cause of a range of major mental illnesses, including posttraumatic stress disorder (PTSD), alcoholism, depression, and anxiety (www.cdc.gov/ace). Moreover, early adversity is strongly associated with poorer response to treatment, increased chronicity of symptoms, and suicide risk (Dube et al., 2001, Zlotnick et al., 2001, Brown et al., 2014). Youth exposed to adverse childhood experiences are at a greater risk for learning and behavioral problems; they are more likely to have poorer school performance (DelaneyBlack et al., 2002), more days of school absence (Hurt et al., 2001), and decreased verbal IQ (Saigh et al., 2006). Estimates of prevalence of traumatic experiences in children range from 15-60\% (Kessler et al., 1995, Dube et al., 2001, Stein et al., 2010), but prevailing concern about underreporting suggest these numbers may be even higher. Herein, the fact that early adversity represents a chief public health concern and financial burden is indisputable.

\section{Early brain development}

Neuroimaging techniques have been central to characterization of normal brain development in domains of structure, function, and connectivity. Longitudinal structural magnetic imaging (MRI) studies show a linear increase with age in white matter that is most pronounced between early childhood and adolescence (Giedd and Rapoport, 2010). Myelination of the corpus callosum, the primary white matter tract in the brain that controls inter-hemispheric communication, occurs in a rostral-caudal sequence and continues throughout childhood into early adulthood (Giedd et al., 1996). In contrast, gray matter follows an inverted U-shaped pattern of change, rapidly increasing until about age 10 then decreasing thereafter (Sowell et al., 2003). This pattern presumably reflects concurrent and complementary processes of axonal myelination and synaptic pruning (Sowell et al., 2001). Diffusion tensor imaging (DTI) and functional connectivity MRI (fcMRI) data highlight a transition from short-range to long-range wiring in the brain through adolescence, thought to reflect increasingly optimized brain neurocircuitry (Supekar et al., 2009). In addition to the 
strengthening of long-range connections, increasing regional specialization and experiencedependent plasticity also play an intricate and commensurate role in brain maturation (Kelly et al., 2009, Stevens et al., 2009). Extended discussion of human brain developmental processes is available in prior influential works (see Paus, 2005, Houston et al., 2014).

Drilling down deeper into brain maturation we find that brain maturation is linked to pubertal status (Blakemore et al., 2010), that different structures in adjacent brain regions mature at different rates (Gogtay et al., 2004, Goddings et al., 2014), and that neurodevelopmental connectional and structural trajectories differ between the sexes (Goddings et al., 2014, Simmonds et al., 2014). Knowledge that the human brain varies along these multifaceted dimensions (age, region, sex) adds a level of complexity to consideration of the impacts of trauma in the early developing brain. By the nature of their early and upstream effects, disturbances affecting the brain in time-sensitive developmental periods can have lasting or widespread organizational impact. Increased vulnerability is ascribed to periods of rapid maturation (Paus et al., 2008, Tottenham, 2014), but empirical research is needed to unpack interactions between stress/adversity and sensitive periods in human development. Also, because adjacent brain structures mature at different rates, it is likely that individual neural regions and circuits have distinct windows of vulnerability to effects of traumatic stress. Thus, the developmental timing of traumatic events and sex of the victim are relevant to behavioral and neurological outcomes (Tottenham and Sheridan, 2009), compelling the need for longitudinal and sex-specific developmental research.

\section{Longitudinal developmental research}

The vast majority of neuroimaging studies in children and adolescents (youth) are crosssectional and draw on community-based samples. Cross-sectional studies of development test subjects spanning an array of ages, whereas longitudinal studies take repeat measurements, testing subjects across multiple time points. Longitudinal designs are less likely to suffer from cohort effects, wherein intra-individual differences have the potential to eclipse age-related effects. Fitting with this, longitudinal designs are better able to differentiate inter- and intra-individual effects, leading to greater variability in effects of interest and improved power (Rogosa et al., 1982). Thus, statistical inference is superior in longitudinal research, because it is possible to account for inter-individual differences from any number of sources to better parse interactions between experience and age-related developmental change.

Additional distinct benefits of longitudinal research are the ability to associate phenotypic and neurological change over time, and to address non-linear developmental change. The former enables identification of deviations or convergence in relations between factors across time. The latter enables sensitivity to varied maturational trajectories. Linear modeling is appropriate for systems with increasing or decreasing change with no sign of slowing, but not appropriate for systems better described in terms of spurts, halts, and/or reversals - all of which are evident in development. Non-linear inverse and quadratic models have been used to define human functional neural maturation (Ordaz et al., 2013), and cubic, quadratic and linear models have categorized structural brain development (Shaw et al., 2008). Inverse trajectories describe increase or decrease with age, but also allow for shifts in 
magnitude of change across development (cf. Ordaz et al., 2013). In contrast, quadratic trajectories depict increase or decrease that ceases at a particular point then reverses direction. Cubic trajectories are even more complex, and can account for a peak followed by a leveling off into adulthood, as depicted by the second point of inflection (Shaw et al., 2008). Clearly, a variety of models are necessary to best capture distinct processes present in human development (Di Martino et al., 2014).

Discussion of longitudinal approaches is germane to the current review because systematic, longitudinal studies of neurodevelopmental impacts of traumatic adversity are scarce, despite their potential for translational benefit (for example, see Tam et al., 2015). Practical constraints of longitudinal research are rampant (cf. Thomson and Holland, 2003), and at least some of these are amplified in human neuroimaging research. Heightened neuroimaging costs translate into greater attrition expense and at the same time restrict ability to oversample to mitigate potential attrition effects. In addition, best practices for image acquisition are continually changing, spurring ongoing upgrades of scanner software and hardware with potential to introduce methodological error into estimates of developmental change over time. Fortunately, there are statistical and study design attributes that can allay some of these concerns, some of which are drawn from solutions presented for combining data collected across scan platforms (Glover et al., 2012) or for calibrating nonneuronal aspects of individual acquisitions (Thomason et al., 2007). Thus, longitudinal research is not presented as an easy solution, yet herein, we attempt to describe ways in which the longitudinal approach has the potential to move the field of neurodevelopmental traumatic adversity from topological phenomenology to etiological nosology (see also, Di Martino et al., 2014). As stated above, longitudinal studies can capture unique aspects of brain development associated with more negative versus more resilient clinical or phenotypic outcomes and can make attributions of causality. This sounds optimal, but achieving a parsimonious account of the impacts of trauma on brain development will be difficult. More likely, we will discover that many pathways exist between early adversity and brain maturation. Concerns about complexity aside, we maintain that discovery in this context is the only road toward individually tailored and maximally effective intervention and prevention.

In parallel to emphatic calls for increased longitudinal developmental research, recent commentaries (Falk et al., 2013) and reviews (Di Martino et al., 2014) reveal an emergent widespread sentiment that well-characterized, large, representative samples are badly needed in neurodevelopmental research. These topics are not the focus of the current review, but have bearing on what can be discovered about the impacts of trauma in the developing brain. Strong phenotypic, genetic, and physiological characterization anchor neural effects in a wider context. Large, representative samples can unearth new knowledge about cross-cutting impacts. Recruitment approaches in current and past studies of trauma have primarily evaluated narrow demographic groups, many of which involve some form of selection bias. There are difficult decisions to be made around selectivity in recruitment, a topic we more fully address in the next section. Arguments are justified both for broad representation and for focused selection, but conversation in this area is currently lacking. There is a responsibility to evaluate and acknowledge how recruitment decisions have bearing on interpretations drawn from results. 


\section{Trauma associated disruption in neural volume, structure and connectivity}

The primary neural systems implicated in trauma exposure are the neural stress pathway and the emotion processing and regulation pathway (Hart and Rubia, 2012). In addition, cognitive control, selective attention, and reward processing pathways have been identified as conduits of trauma and stress related change (Mueller et al., 2010, Pechtel and Pizzagalli, 2011, McLaughlin et al., 2014b, Lim et al., 2015, Marusak et al., 2015a). While these are often conceptualized as unique pathways, systems of the brain are highly integrated. Changes in one pathway will almost certainly have bearing on others. Moreover, examination of these pathways typically centers on core system constituents. This happens, in part, because it is hard to draw lines at points where one neural system begins and another ends. Here, we provide a brief review of alterations in neural systems most frequently associated with traumatic stress.

The stress pathway is one of the most obvious candidates when considering the impact of trauma on animal biology. Although stress induces responses across the entire body, the brain is the central regulator of the stress response through action of the hypothalamicpituitary-adrenal (HPA) axis. The HPA axis mobilizes endocrine, metabolic, cardiovascular, and immune system responses by way of glucocorticoids, such as cortisol, the hormonal end product of the HPA axis in humans (Romeo and McEwen, 2006). The hippocampus, situated bilaterally in medial temporal lobe, is replete with glucocorticoid receptors and is on the receiving end of the stress hormone cascade (McEwen and Milner, 2007, McEwen, 2012). Repeat hits to this receptor system are associated with atrophy, reduced neurogenesis and synaptogenesis, and protein expression modification in animals (McEwen, 2012). Fitting with this, combat-related PTSD is associated with reductions in hippocampal volume in humans (Bremner et al., 1997), a finding that has now been replicated more that 20 times (Woon and Hedges, 2008). These data reveal a tight association between response to trauma and hippocampal integrity, but do not exclude the possibility that smaller hippocampal volumes are a preexisting risk factor for PTSD.

The relationship between trauma exposure and hippocampus volumetric reduction in children and adolescents is less clear. Some studies show hippocampal reduction in children exposed to early stress (i.e., physical abuse, neglect, low SES; Hanson et al., 2015), but other studies (Keding and Herringa, 2015) and meta-analyses (Woon et al., 2010) do not reproduce this effect. An interesting notion with potential to reconcile these inconsistencies is that traumatic adversity related hippocampal reduction is late emerging. That is, select morphological changes associated with early stress may not be manifest until later in life (Tottenham and Sheridan, 2009). This idea is corroborated by the 2015 study from Keding and Herringa showing that age positively predicted hippocampal volume in healthy youth but negatively predicted volume in youth with PTSD.

Dysregulated HPA axis function has been linked to emotional psychopathology including anxiety (Kallen et al., 2008), depression (Palazidou, 2012) and PTSD (Shea et al., 2005). Youth that develop post-traumatic stress symptoms have higher levels of cortisol than youth without trauma history (Carrion and Wong, 2012). Increased fearful vigilance and anxiety in a threatening environment can be adaptive in the short term, yet under chronic stress, 
persistent activation may become maladaptive. Emerging evidence suggests that repeat traumatic exposure may evoke different responses in the stress system machinery, leading to the prevailing theory that stress-related endocrine function may be dependent upon trauma type and duration (Carrion and Kletter, 2012).

Another pathway that has received substantial attention and shown significant linkages to traumatic experiences is the limbic, emotion regulatory brain network. In particular, the prefrontal cortex (PFC), the anterior cingulate cortex (ACC), and the amygdala are central to emotional responding. Impoverished grey matter volume has been observed in the PFC in youth that experience trauma (e.g. orbitofrontal cortex; Carrion et al., 2009, Hanson et al., 2010, Lim et al., 2014), and larger amygdala volume has been observed in children reared in orphanages (Mehta et al., 2009, Tottenham et al., 2010, although see Sheridan et al., 2012) and those exposed to maternal depressive symptomology (Lupien et al., 2011). Animal research corroborates this effect, demonstrating neuropil expansion in the amygdala of animals subjected to chronic stress (Vyas et al., 2002). Combined differences in PFC and amygdala volume are noteworthy because they are major constituents of brain emotion circuitry. Medial PFC receives inputs from lateral regions, such as the dorsolateral cortex, that help to regulate amygdala response via direct and indirect (e.g., ACC) inhibition (see review by Kalisch, 2009).

The amygdala is highly reactive to threat, rapidly alerting the animal to dangerous conditions through initiation of the neural stress cascade (LeDoux, 2003). Amygdala activation engages stress hormone release and engagement of the sympathetic nervous system such to prepare the fight or flight response (Rodrigues et al., 2009). Furthermore, the amygdala plays a central role in ascribing emotional significance of stimuli and, through intricate reciprocal connections with the hippocampus, plays a key role in the formation of emotional memories (Davis and Whalen, 2001, Phelps and LeDoux, 2005). Task-based functional magnetic resonance imaging (fMRI) studies reveal increased response in the amygdala and hippocampus in individuals that experience early adversity (Maheu et al., 2010, McCrory et al., 2011, Dannlowski et al., 2012, Garrett et al., 2012, Marusak et al., 2015b) suggesting that early trauma may alter neurobiological ascription of salience to emotional cues. For example, history of childhood maltreatment in 145 adults was associated with amygdala hyper-responsiveness to threatening facial expressions (see Figure 1; Dannlowski et al., 2012).

Neural pathways that subserve processing and evaluation of reward are a third common area of inquiry in the search to understand biological consequences of early traumatic adversity. An emerging theory informed by animal and human research is that reduced sensitivity to reward is an intermediate phenotype that links early stress exposure to affective disorder (Bogdan et al., 2013). Structural and functional changes are documented in the dopaminergic reward centers in the brain of animals subjected to early stress (Hall et al., 1999, Chocyk et al., 2015). Further, reduced response to reward in the ventral striatum, a key brain reward center, is documented in early-institutionalized youth (Goff et al., 2013) and adults reporting histories of early stress (Corral-Frías et al., 2015). We and others have found that trauma-related changes in brain function and connectivity correspond with diminished experience of positive affect rather than heightened negative affect (Nikolova et al., 2012, 
Marusak et al., 2015b), suggesting that robust brain reward function and associated levels of positive affect may be protective against stress-related psychopathology. Consistent with this, higher striatal response to reward is associated with reduced PTSD symptomology in combat-exposed soldiers (Admon et al., 2013). Individual differences in dopamine systems and brain reward activity is linked to stress-related HPA axis activation (Bogdan et al., 2013), highlighting again the intertwined nature of these systems. Identifying individual difference variables that confer vulnerability or resiliency to stress-related anhedonia will be an important target for future research.

Beyond differences in brain regions that subserve cognitive and affective processing, many studies have demonstrated that the connectional architecture of the brain also differs in those exposed to severe trauma. Evaluation of neural system connectivity can provide localized information about select network integrity and also global information about overall information transfer efficiency. Connectivity analyses can also be applied to quantify degree of independence and/or overlap between neural networks, providing knowledge about shared information processing across neural systems. As such, analysis of neural connectivity in individuals that experience trauma adds a vital dimension to characterization of the imprint of trauma in the human brain. Altered functional connectivity has been demonstrated in adults with history of early childhood trauma (with comorbid PTSD; Bluhm et al., 2009), childhood neglect (with comorbid major depressive disorder; Wang et al., 2013), and emotional maltreatment (van der Werff et al., 2012). Several studies of early adversity have reported altered connectivity in an important regulatory emotion pathway linking the amygdala and ventromedial PFC in individuals that experience early adversity. For example, Burghy and colleagues evaluated connectivity in 57 young adults (mean age $\pm \mathrm{sd}=18.44$ \pm 0.19 years) and observed decreased frontoamygdala connectivity in those exposed to maternal stress during infancy. Lower connectivity was, in turn, related to self-reported anxiety and depression symptoms, and to elevated childhood cortisol, in females (Burghy et al., 2012). Altered frontoamygdala functional connectivity has also been observed in previously institutionalized children (mean age $\pm \mathrm{sd}=13.2 \pm 5.2$ years) while viewing emotional face stimuli (Gee et al., 2013), and urban, trauma-exposed youth (mean age $\pm \mathrm{sd}=$ $12.6 \pm 2.1$ years) during resting-state fMRI (see Figure 2; Thomason et al., 2015).

There is also evidence that the default mode (DMN) and salience networks (SN) of the brain are differently organized in individuals that experience early traumatic stress. Comprised of medial PFC, posterior cingulate, and parietal and medial temporal cortices, the DMN exhibits heightened activity during periods of rest and self-referential or introspective thought (Raichle et al., 2001, Andrews-Hanna et al., 2014). In complementary fashion, the salience network (SN), comprised of the anterior cingulate and bilateral insular cortices, responds when presented with visceral, external stimuli, or events likely to evoke salient physical or emotional response (Seeley et al., 2007, Thomason et al., 2011). Philip and colleagues found reduced connectivity between nodes of the DMN (2013) and weaker down regulation of DMN activity during a cognitively demanding working memory task (Philip et al., 2012) in adults with history of early life stress. Results obtained by our group demonstrate that connectivity within the SN is enhanced and that connectivity between the SN and DMN is diminished in trauma-exposed children (Marusak et al., 2015a). These findings provide a valuable heuristic understanding of neural outcomes following exposure 
to stress and trauma in early life and may help us to generate new hypotheses about what disposes some individuals to more deleterious trauma-related outcomes. Specifically, these observations arouse ideas about possible shifts in information processing or perception in individuals that endure trauma. For example, increased signal covariance in the SN could reflect a large-scale neural oscillator in the $\mathrm{SN}$ system that results in exaggerated attribution to salience in commonplace events (Menon, 2011, Uddin, 2015). It is these ideas that motivate further work to decompose trauma-related illness into constituent alterations in neural processing. Later sections of this review call for more anatomical and experiential specificity when making these attributions, and for bridging brain and behavioral phenotype. The latter brings experiential significance to observed neural effects.

\section{Dissociation of trauma types and of trauma versus chronic stress}

A major challenge for research into budding neurobiology of trauma is selection of research participants or groups. Arguments for narrowing trauma into select categories as a means for comparison butt up against more naturalistic approaches where trauma is multifaceted and complex. Selection of narrow classes may bring us closer to mechanistic understanding of select cases, as this approach does not dilute discovery by mixing potentially unique pathways. However, trauma rarely occurs in isolation. More often, one individual experiences multiple forms of trauma and may also be exposed to chronic stress and adversity. Beyond this, response to trauma varies widely between individuals.

A prominent model of adversity and neural development distinguishes deprivation and threat as dimensions of environmental experience likely to differently influence neural development (McLaughlin et al., 2014a, Sheridan and McLaughlin, 2014). Deprivation embodies absence of adaptive environmental inputs, whereas threat represents harmful experiences that compromise physical integrity. Deprivation and threat are amongst the most frequently experienced trauma types and the idea that they may have distinct consequences is well reasoned.

Enhanced understanding of consequences of deprivation has resulted from human and animal research, which have developed in parallel. Consistent results have emanated from these lines of inquiry. Animals deprived of sensory inputs undergo reduced neuronal pruning and manifest neural organization best suited to low complexity environments. Animals deprived of early maternal care also appear more anxious and show alterations in amygdala, hippocampus, and medial PFC structure and function (Tottenham and Sheridan, 2009, Eiland and McEwen, 2012). Similar results are reported in early-institutionalized children. Institutionalized children show reduced cortical volume and altered amygdala structure and function (Chugani et al., 2001, Tottenham, 2012).

Despite similarities in animal and human literatures, deprivation in humans is highly convoluted in contrast to experimentally controlled conditions endured by animals. In humans, deprivation encompasses any number of things, many of which frequently co-occur. Forms of human deprivation include, for example, absence of early attachment bonds (inconsistent caregiving), lack of provision for basic needs (scarce food, clothing, shelter), or deficient environmental inputs (reduced linguistic input). Clearly, one challenge of breaking 
trauma down into core components is the question of how far to go when segmenting experiences into unique kinds. At some point we fall down a rabbit hole of examination and find it difficult to connect with cross-cutting themes. In addition, forms of deprivation, such as those enumerated above, are not likely to contribute equally to observed outcomes. For example, deficient early-attachment is likely more coupled to later socioemotional difficulties, whereas deficient linguistic inputs are likely to link to cognitive or expressive delays. Nonetheless, subdivision of individuals along core dimensions of trauma, such as deprivation and threat, is likely to advance understanding.

Observations about neural underpinnings of threat-related trauma emphasize lasting changes in neural circuits that undergird emotional learning. Changes observed include atypical response to emotional stimuli, reduced hippocampal response during declarative memory retrieval (Carrion et al., 2010), amplified response to stimuli depicting negative emotions (Pollak and Sinha, 2002, McCrory et al., 2011), and altered connectivity in amygdalaprefrontal circuitry (Thomason et al., 2015). Animal studies further elaborate the basis of these observations demonstrating, for example, that animals exposed to chronic restraint stress show reduced dendritic elaboration in hippocampus and medial PFC (mPFC) pyramidal cells (Eiland et al., 2012).

Three additional considerations arise in pursuit of understanding unique impacts of early trauma on the developing brain. These are: the role of chronic stress in driving neural effects; the interface between symptomology and neural traits; and the influence of age of onset and chronicity on observed outcomes. All of these are likely to interact with traumatic events to alter development of key neural systems; however, understanding of these interactions is currently lacking. Given the intermingling of factors that could influence individual outcomes, selection of participants for comparison is therefore complex. It is particularly difficult to control for the presence of chronic stress in studies of early trauma in part because communities high in trauma prevalence also tend to be high in general adversity and stress.

The double-hit of trauma and chronic stress can have any number of effects (e.g., additive, synergistic, buffering), all with potential to alter measurements in neural pathways of greatest interest. Decisions about whether to equate or control effects of stress within and between study groups are not clear-cut. For example, selection of control participants from the same environment is likely to yield results that better reflect unique consequences of trauma. However, it follows to reason that in such a comparison both groups differ from what is typical. Further, definitions of trauma can be complex. Take the following as an example. A study that addresses the impact of interpersonal victimization (sexual, physical, emotional abuse) on child neural connectivity screens two participants for inclusion. Parent reports that 10-year-old child A (risk case) was repeatedly sexually assaulted at age 5 by a cousin that stayed in the house over a 5 month period. Child A reports not remembering the event and does not show posttraumatic symptomology or negative affect. 10-year-old child B (control case) witnessed "angry and yelling" fights over a 7 month period between mother and her boyfriend at age 7 , and at age 8 child and mother spent 6 months living with friends and family members while mom established a secure living situation. Child B reports subthreshold anxiety symptomology and describes sometimes "reliving" negative 
experiences. Child B would not qualify as a risk case as there is no history of being a victim of interpersonal abuse, yet this child has been exposed to conditions of compromised security and demonstrates mild but sustained emotional and somatic concerns.

Determinations about pathways of risk are muddied when control experiences overlap features that may themselves be causal drivers of change. This example also highlights the individual and elaborate nature of a given trauma narrative. All are distinctive stories to be considered and understood in order to inform analytic approaches and to interpret observed effects. Cognitive psychology and human neuroscience study designs rarely consider results at the individual subject level. Instead, results are most often determined and reported using group level statistical approaches.

Subject selection and interpretation concerns are amplified in neuroimaging studies where samples tend to be small, typically with fewer than 50 participants. Given power constraints, variability in participant characteristics (e.g., age, pubertal status, IQ, chronic stress) that can confound observed effects are difficult to address. When considered a priori, one solution is to narrow subject selection criteria to reduce variation in these characteristics, for example, by restricting the age range. Another solution is to address these potentially confounding variables post hoc. For instance, in secondary analyses it is possible to isolate main effects that relate to participant characteristics or to confirm whether main effects replicate in subsamples deliberately matched on these characteristics. These strategies have been employed in prior fMRI studies of youth with histories of trauma (Marusak et al., 2015a, Marusak et al., 2015b, Thomason et al., 2015).

The possible influence of chronic stress in studies of early life trauma is more difficult to address. Strategies highlighted above assume that potential confounds are easily quantified. Developing valid measures of stressful life events has plagued the field for decades (e.g., Dohrenwend, 2006), and measuring chronic stress may be even more convoluted. Stress is a complex construct that refers both to environmental factors and also the individual's psychological and physiological responses over time (Pacak and Palkovits, 2001, Monroe, 2008). The literature is replete with examples of subject or population specific inventories of environmental stress (e.g., asthma and school stress inventories, Röder et al., 2002), but consensus on chronic stress measurement has not been reached. One possible proxy of chronic stress is neighborhood disadvantage, which captures indirect information about access to resources and community structure, which are correlates of stress. However, effects of neighborhood disadvantage can vary with features more difficult to measure such as community disorganization, collective efficacy, and social capital (Haines et al., 2011), raising concern about sensitivity. Weaknesses aside, neighborhood disadvantage and sociodemographic information can account for some of the variance that would be assumed by chronic stress and therefore can serve as useful factors in studies of early traumatic adversity. Another solution is to collect physiological as well as behavioral or self-report measures of stress (e.g., cortisol, heart rate, telomere length, cytokines). These can reflect the biological embedding of stress, which serves the overarching purpose of better characterization of stress in the individual. See (Dohrenwend, 2006, Monroe, 2008, Piazza et al., 2010, Shalev et al., 2013) for further discussion. 
Altogether, it is difficult to constrain trauma-types, to disentangle symptomology and experience, and to mitigate the co-mingling of wider environmental stress. As such, discovery about neurological sequela following trauma is best derived at the individual study and aggregate level, and results are best interpreted considerate of study design and analytic approach.

\section{Need for anatomical specificity in trauma-related effects}

Moving forward in our understanding of how trauma impacts the developing brain requires a shift in the way findings are conveyed. Extant neuroimaging research has almost universally described the location of trauma-related effects in terms of large, general brain areas (e.g., ACC, parietal cortex, insula). Peak stereotaxic coordinates are frequently also reported, but when these are compared across studies it is apparent that while the same overall label is given, the peak of the effect can vary substantially. There are several examples in the literature that illustrate this point (Northoff et al., 2006, Etkin et al., 2011, Ochsner et al., 2012). This approach not only obscures meaningful boundaries between brain regions, but also implicitly assumes the same brain circuitries are involved. Lack of specificity both with regard to the brain region and neuroanatomic makeup of the circuit within which the region is embedded constitute critical barriers to identifying the neural systems affected by early trauma, and ultimately, risk for stress-related psychopathology.

Studies of trauma, and more generally emotional psychopathology, implicate alterations in medial PFC, ACC, and amygdala structure, function, and connectivity. For example, altered connectivity between amygdala and $\mathrm{mPFC}$ is reported across a range of psychopathology risk factors (e.g., childhood trauma exposure), and, additionally, across internalizing conditions (e.g., PTSD, depression). Aggregation of results would suggest these are reliable effects, yet mPFC, ACC and amygdala encompass heterogeneous subregions with unique functions, cellular compositions, and/or positions within brain circuitry. Closer evaluation of reported peaks confirms that phenotypically relevant regional substructure can be extracted from existing data. In illustration of this point we used GingerALE software (Turkeltaub et al., 2002, Eickhoff et al., 2009) to perform brief meta-analyses of 29 affective neuroscience resting-state fcMRI studies that observed disruptions in amygdala-mPFC/ACC connectivity. We found that peak effects are centered in 3 separable, focal subareas of the ACC. We further confirmed that these discrete subregions have unique connectivity profiles. These subareas also show unique patterns of neural co-activation during tasks, and are associated with separable behavioral processes (see Figure 3). Taken together, these observations indicate that these are dissociable brain regions that when isolated have unique relevance to connectivity, co-activation, and behavior.

While parcellation of the brain into separable subregions has long been a goal of human neuroscience, best practices continue to evolve. For more than a century, neuroscientists have relied on cytoarchitectonic (histological) divisions of the cortex published by neurologist, Korbinian Brodmann, in the early 1900's (Brodmann, 1909). These designations are frequently included with report fMRI coordinates. However, Brodmann's labored inquisition was limited; for example, his segregation was constrained to cortical but 
not subcortical brain regions. It is almost counterintuitive that with the major advances in neuroimaging we remain reliant on the dated Brodmann designations.

Since Brodmann's time, more sensitive microstructural mapping techniques such as neurotransmitter receptor binding, myelin composition, and gene expression have been developed. There are now a number of publicly available 3D multimodal brain atlases that allow registration of fMRI data into cyto-, myelo-, and chemo-architectonic maps, derived from other data sources. For example, the Eickhoff-Zilles atlas distributed with SPM Anatomy Toolbox (Eickhoff et al., 2005) and the Harvard-Oxford atlas (Desikan et al., 2006) distributed with FSL software are increasingly used for fMRI processing and interpretation.

An alternative to contextualizing observed effects within available structural atlases is to evaluate data as it compares to results aggregated from hundreds or thousands of prior functional studies. For example, data registries (e.g., BrainMap, Neurosynth) avail opportunity to model and query libraries of fMRI results to achieve deeper understanding of how neuroimaging findings inhabit larger operational frameworks. In addition, large neuroimaging cohorts have been used to generate parcellation schemes that are publicly available. For example, efforts by the Human Connectome Project have lead to a publicly available summary of functional connectivity in 468 subjects (Van Essen et al., 2012). Parcellation based on functional connectivity is interesting because instead of designation based on physical structures, this method conveys information about coordination of activity across brain areas. An interesting question then becomes how to integrate use of this information in our processing schemes. These data need to be developed into easily implemented tools that can improve our ability to incorporate our results into a whole brain architecture, one that may distinguish results across studies from one another in meaningful ways. It is also possible to perform additional processing steps within the data set to learn about parcellation or network connectivity specific to the study sample. For example, spatial spectral clustering is a data driven approach for parcellating the brain into different regions based on functional profiles computed across the cohort (Craddock et al., 2012). Others have developed methods for considering results based on intrinsic functional networks within the group (Khullar et al., 2011). Data set specific strategies are particularly valuable when studying cases for which standard atlases would not be appropriate or are not yet available.

In summary, more precise localization and more in-depth contextualization will improve our ability to gain knowledge from f/fcMRI assessment of neural correlates of trauma and associated emotional psychopathology. This claim is not specific to evaluation of trauma, but may propel this area forward if effectively implemented. In particular, we note wide variation in reported localization of trauma-related effects along midline prefrontal structures. Differences between studies may be meaningful, and closer assessment of these can generate new thinking about specificity of effects and interaction within a more expansive neurological framework. 


\section{Conclusions}

A growing body of research describes altered neurological structure and function in individuals that experience early emotional trauma. In this review, we present an overview of what has been learned and provide suggestions about next steps. We describe prior results in children and adolescents that support a model in which trauma early in life alters neural circuits consistently implicated in emotional health. That is, effects observed in individuals that experience trauma resemble those described in psychopathology. These are hyperresponsiveness in medial temporal components of limbic circuitry, hypo-responsiveness in medial and lateral prefrontal regions associated with regulating limbic response, and decreased engagement of components of the basal ganglia involved in reward related processing. Alterations in stress regulatory pathways including the hippocampus and hypothalamus are also frequently observed in individuals that experience trauma, and most consistently in adults affected by PTSD. Overlap between neurobiological correlates of trauma-exposure and psychopathology suggests that the brain may be a conduit for the link between early adversity and development of emotional psychology. We are not the first to highlight this inference (e.g., Dannlowski et al., 2012), but more research is needed to further support this conclusion.

We emphasize three areas for advancing understanding of the neurobiological bases of trauma: (1) discovery of neurobehavioral associations within a longitudinal context, (2) dissociation of trauma types and of trauma versus chronic stress, and (3) better localization of neural sequelae considerate of the fine resolution of neural circuitry. Longitudinal research can address several current limitations in the literature. Brain networks evolve, grow and adapt to changing cognitive demands (Bullmore and Sporns, 2012), a meaningful context in which to dissect the neurobiology of trauma. Longitudinal examination is needed to evaluate prevailing theory that neural mechanisms that undergird emotional illness may mediate correspondence between severe early adversity and emergence of emotional disorder.

We relay an emergent framework in which dissociable trauma types are hypothesized to impact distinct, rationally-informed neural systems (McLaughlin et al., 2014a, Sheridan and McLaughlin, 2014). In line with this, we discuss the long-standing challenge of separating effects of chronic stress and trauma, as these are often intertwined. We convey that closer investigation of trauma type, developmental timing, and event duration may lead to a more parsimonious account of the neurobiology of trauma. We offer this suggestion with two significant caveats. The first is that in the practice of dissecting trauma into narrow classes, it is difficult to draw lines between types of experiences, and difficult to isolate "pure" forms of trauma. Another consideration is that trauma is almost by definition embedded in the context of high-stress environments and also occurs more frequently in environments high in sociodemographic risk (Gillespie et al., 2009). These real-world environmental variables are meaningful aspects of the role of trauma in shaping the human experience. To remove them from the analytic equation may reduce the ecological validity of observed effects.

We present concrete methods for applying advances in neuroimaging analytic and approach strategies to more precisely determine the neurobiological correlates of trauma. Brodmann 
himself asserted that regionally specific disturbances will be important for understanding psychiatric disorders caused by pathological insults during brain development (Brodmann et al., 1914). It is still the case that more precise spatial attribution will advance understanding of the biological embedding of trauma and inform future research. It will also aid development of targeted interventions - a much needed area for the 35 million US children afflicted by early adversity (Child and Adolescent Health Management Initiative; 2012). These are encouraging directions for unearthing key brain-behavior relations in youth exposed to trauma.

\title{
Acknowledgments
}

This work was supported by the NIH National Institute of Environmental Health Sciences awards P30 ES020957 and R21 ES026022 (MET).

\author{
Abbreviations \\ PTSD Post traumatic stress disorder \\ fcMRI Functional connectivity magnetic resonance imaging \\ fMRI Functional magnetic resonance imaging \\ ACC Anterior cingulate cortex \\ mPFC Medial prefrontal cortex \\ DMN Default mode network \\ SN Salience network
}

\section{References}

2011/12 National Survey of Children's Health. Child and Adolescent Health Measurement Initiative. 2012

Admon R, Lubin G, Rosenblatt JD, Stern O, Kahn I, Assaf M, Hendler T. Imbalanced neural responsivity to risk and reward indicates stress vulnerability in humans. Cerebral cortex (New York, NY : 1991). 2013; 23:28-35.

Andrews-Hanna JR, Smallwood J, Spreng RN. The default network and self-generated thought: component processes, dynamic control, and clinical relevance. Annals of the New York Academy of Sciences. 2014; 1316:29-52. [PubMed: 24502540]

Blakemore SJ, Burnett S, Dahl RE. The role of puberty in the developing adolescent brain. Hum Brain Mapp. 2010; 31:926-933. [PubMed: 20496383]

Bluhm RL, Williamson PC, Osuch EA, Frewen PA, Stevens TK, Boksman K, Neufeld RW, Theberge J, Lanius RA. Alterations in default network connectivity in posttraumatic stress disorder related to early-life trauma. J Psychiatry Neurosci. 2009; 34:187-194. [PubMed: 19448848]

Bogdan R, Nikolova YS, Pizzagalli DA. Neurogenetics of Depression: A Focus on Reward Processing and Stress Sensitivity. Neurobiology of disease. 2013; 52:12-23. [PubMed: 22659304]

Bremner JD, Randall P, Vermetten E, Staib L, Bronen RA, Mazure C, Capelli S, McCarthy G, Innis $\mathrm{RB}$, Charney DS. Magnetic resonance imaging-based measurement of hippocampal volume in posttraumatic stress disorder related to childhood physical and sexual abuse--a preliminary report. Biol Psychiatry. 1997; 41:23-32. [PubMed: 8988792]

Brodmann, K. Vergleichende Lokalisationslehre der Großhirnrinde. Leipzig: Barth; 1909. 
Brodmann, k; Hauptmann, A.; knoblauch, A.; Krause, F. Die Allgemeine Chirurgie Der Gehirnkrankheiten: Ferdinand Enke. 1914.

Brown VM, Labar KS, Haswell CC, Gold AL, Mid-Atlantic MW, Beall SK, Van Voorhees E, Marx CE, Calhoun PS, Fairbank JA, Green KT, Tupler LA, Weiner RD, Beckham JC, Brancu M, Hoerle JM, Pender M, Kudler H, Swinkels CM, Nieuwsma JA, Runnals JJ, Youssef NA, McDonald SD, Davison R, Yoash-Gantz R, Taber KH, Hurley R, McCarthy G, Morey RA. Altered resting-state functional connectivity of basolateral and centromedial amygdala complexes in posttraumatic stress disorder. Neuropsychopharmacology : official publication of the American College of Neuropsychopharmacology. 2014; 39:361-369.

Bullmore E, Sporns O. The economy of brain network organization. Nat Rev Neurosci. 2012; 13:336349. [PubMed: 22498897]

Burghy CA, Stodola DE, Ruttle PL, Molloy EK, Armstrong JM, Oler JA, Fox ME, Hayes AS, Kalin NH, Essex MJ, Davidson RJ, Birn RM. Developmental pathways to amygdala-prefrontal function and internalizing symptoms in adolescence. Nature neuroscience. 2012; 15:1736-1741. [PubMed: 23143517]

Carrion VG, Haas BW, Garrett A, Song S, Reiss AL. Reduced hippocampal activity in youth with posttraumatic stress symptoms: an FMRI study. Journal of pediatric psychology. 2010; 35:559569. [PubMed: 19995868]

Carrion VG, Kletter H. Posttraumatic stress disorder: shifting toward a developmental framework. Child and adolescent psychiatric clinics of North America. 2012; 21:573-591. [PubMed: 22800995]

Carrion VG, Weems CF, Watson C, Eliez S, Menon V, Reiss AL. Converging evidence for abnormalities of the prefrontal cortex and evaluation of midsagittal structures in pediatric PTSD: an MRI study. Psychiatry research. 2009; 172:226-234. [PubMed: 19349151]

Carrion VG, Wong SS. Can traumatic stress alter the brain? Understanding the implications of early trauma on brain development and learning. The Journal of adolescent health : official publication of the Society for Adolescent Medicine. 2012; 51:S23-28. [PubMed: 22794529]

Chocyk A, Majcher-Maślanka I, Przyborowska A, Maćkowiak M, Wędzony K. Early-life stress increases the survival of midbrain neurons during postnatal development and enhances rewardrelated and anxiolytic-like behaviors in a sex-dependent fashion. International Journal of Developmental Neuroscience. 2015; 44:33-47. [PubMed: 25980793]

Chugani HT, Behen ME, Muzik O, Juhasz C, Nagy F, Chugani DC. Local brain functional activity following early deprivation: a study of postinstitutionalized Romanian orphans. NeuroImage. 2001; 14:1290-1301. [PubMed: 11707085]

Clarke, AM.; Clarke, ADB. Early Experience and the Life Path. Jessica Kinglsey Publishers; 2000.

Corral-Frías NS, Nikolova YS, Michalski LJ, Baranger DAA, Hariri AR, Bogdan R. Stress-related anhedonia is associated with ventral striatum reactivity to reward and transdiagnostic psychiatric symptomatology. Psychological Medicine. 2015:1-13. FirstView.

Craddock RC, James GA, Holtzheimer PE 3rd, Hu XP, Mayberg HS. A whole brain fMRI atlas generated via spatially constrained spectral clustering. Hum Brain Mapp. 2012; 33:1914-1928. [PubMed: 21769991]

Dannlowski U, Stuhrmann A, Beutelmann V, Zwanzger P, Lenzen T, Grotegerd D, Domschke K, Hohoff C, Ohrmann P, Bauer J, Lindner C, Postert C, Konrad C, Arolt V, Heindel W, Suslow T, Kugel H. Limbic scars: long-term consequences of childhood maltreatment revealed by functional and structural magnetic resonance imaging. Biological psychiatry. 2012; 71:286-293. [PubMed: 22112927]

Davis M, Whalen PJ. The amygdala: vigilance and emotion. Molecular psychiatry. 2001; 6:13-34. [PubMed: 11244481]

Delaney-Black V, Covington C, Ondersma SJ, Nordstrom-Klee B, Templin T, Ager J, Janisse J, Sokol RJ. Violence exposure, trauma, and IQ and/or reading deficits among urban children. Archives of pediatrics \& adolescent medicine. 2002; 156:280-285. [PubMed: 11876674]

Desikan RS, Segonne F, Fischl B, Quinn BT, Dickerson BC, Blacker D, Buckner RL, Dale AM, Maguire RP, Hyman BT, Albert MS, Killiany RJ. An automated labeling system for subdividing 
the human cerebral cortex on MRI scans into gyral based regions of interest. NeuroImage. 2006; 31:968-980. [PubMed: 16530430]

Di Martino A, Fair DA, Kelly C, Satterthwaite TD, Castellanos FX, Thomason ME, Craddock RC, Luna B, Leventhal BL, Zuo XN, Milham MP. Unraveling the miswired connectome: a developmental perspective. Neuron. 2014; 83:1335-1353. [PubMed: 25233316]

Dohrenwend BP. Inventorying stressful life events as risk factors for psychopathology: Toward resolution of the problem of intracategory variability. Psychol Bull. 2006; 132:477-495. [PubMed: 16719570]

Dube SR, Anda RF, Felitti VJ, Chapman DP, Williamson DF, Giles WH. Childhood abuse, household dysfunction, and the risk of attempted suicide throughout the life span: findings from the Adverse Childhood Experiences Study. Jama. 2001; 286:3089-3096. [PubMed: 11754674]

Eickhoff SB, Bzdok D, Laird AR, Roski C, Caspers S, Zilles K, Fox PT. Co-activation patterns distinguish cortical modules, their connectivity and functional differentiation. NeuroImage. 2011; 57:938-949. [PubMed: 21609770]

Eickhoff SB, Laird AR, Grefkes C, Wang LE, Zilles K, Fox PT. Coordinate-based activation likelihood estimation meta-analysis of neuroimaging data: a random-effects approach based on empirical estimates of spatial uncertainty. Human brain mapping. 2009; 30:2907-2926. [PubMed: 19172646]

Eickhoff SB, Stephan KE, Mohlberg H, Grefkes C, Fink GR, Amunts K, Zilles K. A new SPM toolbox for combining probabilistic cytoarchitectonic maps and functional imaging data. NeuroImage. 2005; 25:1325-1335. [PubMed: 15850749]

Eiland L, McEwen BS. Early life stress followed by subsequent adult chronic stress potentiates anxiety and blunts hippocampal structural remodeling. Hippocampus. 2012; 22:82-91. [PubMed: 20848608]

Eiland L, Ramroop J, Hill MN, Manley J, McEwen BS. Chronic juvenile stress produces corticolimbic dendritic architectural remodeling and modulates emotional behavior in male and female rats. Psychoneuroendocrinology. 2012; 37:39-47. [PubMed: 21658845]

Etkin A, Egner T, Kalisch R. Emotional processing in anterior cingulate and medial prefrontal cortex. Trends Cogn Sci. 2011; 15:85-93. [PubMed: 21167765]

Falk EB, Hyde LW, Mitchell C, Faul J, Gonzalez R, Heitzeg MM, Keating DP, Langa KM, Martz ME, Maslowsky J, Morrison FJ, Noll DC, Patrick ME, Pfeffer FT, Reuter-Lorenz PA, Thomason ME, Davis-Kean P, Monk CS, Schulenberg J. What is a representative brain? Neuroscience meets population science. Proc Natl Acad Sci U S A. 2013; 110:17615-17622. [PubMed: 24151336]

Felitti VJ, Anda RF, Nordenberg D, Williamson DF, Spitz AM, Edwards V, Koss MP, Marks JS. Relationship of childhood abuse and household dysfunction to many of the leading causes of death in adults. The Adverse Childhood Experiences (ACE) Study. American journal of preventive medicine. 1998; 14:245-258. [PubMed: 9635069]

Garrett AS, Carrion V, Kletter H, Karchemskiy A, Weems CF, Reiss A. Brain activation to facial expressions in youth with PTSD symptoms. Depression and anxiety. 2012; 29:449-459. [PubMed: 22553009]

Gee DG, Gabard-Durnam LJ, Flannery J, Goff B, Humphreys KL, Telzer EH, Hare TA, Bookheimer SY, Tottenham N. Early developmental emergence of human amygdala-prefrontal connectivity after maternal deprivation. Proceedings of the National Academy of Sciences of the United States of America. 2013; 110:15638-15643. [PubMed: 24019460]

Giedd JN, Rapoport JL. Structural MRI of pediatric brain development: what have we learned and where are we going? Neuron. 2010; 67:728-734. [PubMed: 20826305]

Giedd JN, Snell JW, Lange N, Rajapakse JC, Casey BJ, Kozuch PL, Vaituzis AC, Vauss YC, Hamburger SD, Kaysen D, Rapoport JL. Quantitative magnetic resonance imaging of human brain development: ages 4-18. Cereb Cortex. 1996; 6:551-560. [PubMed: 8670681]

Gillespie CF, Bradley B, Mercer K, Smith AK, Conneely K, Gapen M, Weiss T, Schwartz AC, Cubells JF, Ressler KJ. Trauma exposure and stress-related disorders in inner city primary care patients. General hospital psychiatry. 2009; 31:505-514. [PubMed: 19892208]

Glover GH, Mueller BA, Turner JA, van Erp TG, Liu TT, Greve DN, Voyvodic JT, Rasmussen J, Brown GG, Keator DB, Calhoun VD, Lee HJ, Ford JM, Mathalon DH, Diaz M, O'Leary DS, 
Gadde S, Preda A, Lim KO, Wible CG, Stern HS, Belger A, McCarthy G, Ozyurt B, Potkin SG. Function biomedical informatics research network recommendations for prospective multicenter functional MRI studies. Journal of magnetic resonance imaging : JMRI. 2012; 36:39-54. [PubMed: 22314879]

Goddings A-L, Mills KL, Clasen LS, Giedd JN, Viner RM, Blakemore S-J. The influence of puberty on subcortical brain development. NeuroImage. 2014; 88:242-251. [PubMed: 24121203]

Goff B, Gee DG, Telzer EH, Humphreys KL, Gabard-Durnam L, Flannery J, Tottenham N. Reduced nucleus accumbens reactivity and adolescent depression following early-life stress. Neuroscience. 2013; 249:129-138. [PubMed: 23262241]

Gogtay N, Giedd JN, Lusk L, Hayashi KM, Greenstein D, Vaituzis AC, Nugent TF 3rd, Herman DH, Clasen LS, Toga AW, Rapoport JL, Thompson PM. Dynamic mapping of human cortical development during childhood through early adulthood. Proc Natl Acad Sci U S A. 2004; 101:8174-8179. [PubMed: 15148381]

Haines VA, Beggs JJ, Hurlbert JS. Neighborhood disadvantage, network social capital, and depressive symptoms. J Health Soc Behav. 2011; 52:58-73. [PubMed: 21362612]

Hall FS, Wilkinson LS, Humby T, Robbins TW. Maternal deprivation of neonatal rats produces enduring changes in dopamine function. Synapse (New York, NY). 1999; 32:37-43.

Hanson JL, Chung MK, Avants BB, Shirtcliff EA, Gee JC, Davidson RJ, Pollak SD. Early stress is associated with alterations in the orbitofrontal cortex: a tensor-based morphometry investigation of brain structure and behavioral risk. J Neurosci. 2010; 30:7466-7472. [PubMed: 20519521]

Hanson JL, Nacewicz BM, Sutterer MJ, Cayo AA, Schaefer SM, Rudolph KD, Shirtcliff EA, Pollak SD, Davidson RJ. Behavioral problems after early life stress: contributions of the hippocampus and amygdala. Biological psychiatry. 2015; 77:314-323. [PubMed: 24993057]

Hart H, Rubia K. Neuroimaging of child abuse: a critical review. Front Hum Neurosci. 2012; 6:52. [PubMed: 22457645]

Houston SM, Herting MM, Sowell ER. The neurobiology of childhood structural brain development: conception through adulthood. Curr Top Behav Neurosci. 2014; 16:3-17. [PubMed: 24357437]

Hurt H, Malmud E, Brodsky NL, Giannetta J. Exposure to violence: psychological and academic correlates in child witnesses. Archives of pediatrics \& adolescent medicine. 2001; 155:1351-1356. [PubMed: 11732955]

Kalisch R. The functional neuroanatomy of reappraisal: time matters. Neuroscience and biobehavioral reviews. 2009; 33:1215-1226. [PubMed: 19539645]

Kallen VL, Tulen JH, Utens EM, Treffers PD, De Jong FH, Ferdinand RF. Associations between HPA axis functioning and level of anxiety in children and adolescents with an anxiety disorder. Depression and anxiety. 2008; 25:131-141. [PubMed: 17340603]

Keding TJ, Herringa RJ. Abnormal structure of fear circuitry in pediatric post-traumatic stress disorder. Neuropsychopharmacology : official publication of the American College of Neuropsychopharmacology. 2015; 40:537-545. [PubMed: 25212487]

Kelly AM, Di Martino A, Uddin LQ, Shehzad Z, Gee DG, Reiss PT, Margulies DS, Castellanos FX, Milham MP. Development of anterior cingulate functional connectivity from late childhood to early adulthood. Cereb Cortex. 2009; 19:640-657. [PubMed: 18653667]

Kessler RC, Sonnega A, Bromet E, Hughes M, Nelson CB. Posttraumatic stress disorder in the National Comorbidity Survey. Archives of general psychiatry. 1995; 52:1048-1060. [PubMed: 7492257]

Khullar S, Michael AM, Cahill ND, Kiehl KA, Pearlson G, Baum SA, Calhoun VD. ICA-fNORM: Spatial normalization of fMRI data using intrinsic group-ICA networks. Frontiers in systems neuroscience. 2011:5. [PubMed: 21369350]

LeDoux J. The emotional brain, fear, and the amygdala. Cellular and molecular neurobiology. 2003; 23:727-738. [PubMed: 14514027]

Lim L, Hart H, Mehta MA, Simmons A, Mirza K, Rubia K. Neural Correlates of Error Processing in Young People With a History of Severe Childhood Abuse: An fMRI Study. The American journal of psychiatry. 2015 appiajp201514081042.

Lim L, Radua J, Rubia K. Gray matter abnormalities in childhood maltreatment: a voxel-wise metaanalysis. The American journal of psychiatry. 2014; 171:854-863. [PubMed: 24781447] 
Lupien SJ, Parent S, Evans AC, Tremblay RE, Zelazo PD, Corbo V, Pruessner JC, Seguin JR. Larger amygdala but no change in hippocampal volume in 10-year-old children exposed to maternal depressive symptomatology since birth. Proc Natl Acad Sci U S A. 2011; 108:14324-14329. [PubMed: 21844357]

Maheu FS, Dozier M, Guyer AE, Mandell D, Peloso E, Poeth K, Jenness J, Lau JY, Ackerman JP, Pine DS, Ernst M. A preliminary study of medial temporal lobe function in youths with a history of caregiver deprivation and emotional neglect. Cogn Affect Behav Neurosci. 2010; 10:34-49. [PubMed: 20233954]

Marusak HA, Etkin A, Thomason ME. Disrupted insula-based neural circuit organization and conflict interference in trauma-exposed youth. NeuroImage: Clinical. 2015a

Marusak HA, Martin KR, Etkin A, Thomason ME. Childhood trauma exposure disrupts the automatic regulation of emotional processing. Neuropsychopharmacology : official publication of the American College of Neuropsychopharmacology. 2015b; 40:1250-1258. [PubMed: 25413183]

McCrory EJ, De Brito SA, Sebastian CL, Mechelli A, Bird G, Kelly PA, Viding E. Heightened neural reactivity to threat in child victims of family violence. Current biology : CB. 2011; 21:R947-948. [PubMed: 22153160]

McEwen BS. Brain on stress: how the social environment gets under the skin. Proceedings of the National Academy of Sciences of the United States of America. 2012; 109(Suppl 2):17180-17185. [PubMed: 23045648]

McEwen BS, Milner TA. Hippocampal formation: shedding light on the influence of sex and stress on the brain. Brain research reviews. 2007; 55:343-355. [PubMed: 17395265]

McLaughlin KA, Sheridan MA, Lambert HK. Childhood adversity and neural development: deprivation and threat as distinct dimensions of early experience. Neuroscience and biobehavioral reviews. 2014a; 47:578-591. [PubMed: 25454359]

McLaughlin KA, Sheridan MA, Winter W, Fox NA, Zeanah CH, Nelson CA. Widespread reductions in cortical thickness following severe early-life deprivation: a neurodevelopmental pathway to attention-deficit/hyperactivity disorder. Biological psychiatry. 2014b; 76:629-638. [PubMed: 24090797]

Mehta MA, Golembo NI, Nosarti C, Colvert E, Mota A, Williams SC, Rutter M, Sonuga-Barke EJ. Amygdala, hippocampal and corpus callosum size following severe early institutional deprivation: the English and Romanian Adoptees study pilot. Journal of child psychology and psychiatry, and allied disciplines. 2009; 50:943-951.

Menon V. Large-scale brain networks and psychopathology: a unifying triple network model. Trends in cognitive sciences. 2011; 15:483-506. [PubMed: 21908230]

Monroe, SM. Annual Review of Clinical Psychology. Vol. 4. Palo Alto: Annual Reviews; 2008. Modern approaches to conceptualizing and measuring human life stress; p. 33-52.

Mueller SC, Maheu FS, Dozier M, Peloso E, Mandell D, Leibenluft E, Pine DS, Ernst M. Early-life stress is associated with impairment in cognitive control in adolescence: an fMRI study. Neuropsychologia. 2010; 48:3037-3044. [PubMed: 20561537]

Nikolova YS, Bogdan R, Brigidi BD, Hariri AR. Ventral striatum reactivity to reward and recent life stress interact to predict positive affect. Biological psychiatry. 2012; 72:157-163. [PubMed: 22534456]

Northoff G, Heinzel A, de Greck M, Bermpohl F, Dobrowolny H, Panksepp J. Self-referential processing in our brain--a meta-analysis of imaging studies on the self. Neuroimage. 2006; 31:440-457. [PubMed: 16466680]

Ochsner KN, Silvers JA, Buhle JT. Functional imaging studies of emotion regulation: a synthetic review and evolving model of the cognitive control of emotion. Annals of the New York Academy of Sciences. 2012; 1251:E1-24. [PubMed: 23025352]

Ordaz SJ, Foran W, Velanova K, Luna B. Longitudinal growth curves of brain function underlying inhibitory control through adolescence. J Neurosci. 2013; 33:18109-18124. [PubMed: 24227721]

Pacak K, Palkovits M. Stressor specificity of central neuroendocrine responses: implications for stressrelated disorders. Endocrine reviews. 2001; 22:502-548. [PubMed: 11493581]

Palazidou E. The neurobiology of depression. British medical bulletin. 2012; 101:127-145. [PubMed: 22334281] 
Paus T. Mapping brain maturation and cognitive development during adolescence. Trends Cogn Sci. 2005; 9:60-68. [PubMed: 15668098]

Paus T, Keshavan M, Giedd JN. Why do many psychiatric disorders emerge during adolescence? Nat Rev Neurosci. 2008; 9:947-957. [PubMed: 19002191]

Pechtel P, Pizzagalli DA. Effects of early life stress on cognitive and affective function: an integrated review of human literature. Psychopharmacology. 2011; 214:55-70. [PubMed: 20865251]

Phelps EA, LeDoux JE. Contributions of the amygdala to emotion processing: from animal models to human behavior. Neuron. 2005; 48:175-187. [PubMed: 16242399]

Philip NS, Sweet LH, Tyrka AR, Price LH, Bloom RF, Carpenter LL. Decreased default network connectivity is associated with early life stress in medication-free healthy adults. European neuropsychopharmacology : the journal of the European College of Neuropsychopharmacology. 2013; 23:24-32. [PubMed: 23141153]

Philip NS, Sweet LH, Tyrka AR, Price LH, Carpenter LL, Kuras YI, Clark US, Niaura RS. Early life stress is associated with greater default network deactivation during working memory in healthy controls: a preliminary report. Brain imaging and behavior. 2012

Piazza JR, Almeida DM, Dmitrieva NO, Klein LC. Frontiers in the use of biomarkers of health in research on stress and aging. The journals of gerontology Series B, Psychological sciences and social sciences. 2010; 65:513-525.

Pollak SD, Sinha P. Effects of early experience on children's recognition of facial displays of emotion. Developmental psychology. 2002; 38:784-791. [PubMed: 12220055]

Raichle ME, MacLeod AM, Snyder AZ, Powers WJ, Gusnard DA, Shulman GL. A default mode of brain function. Proc Natl Acad Sci U S A. 2001; 98:676-682. [PubMed: 11209064]

Röder I, Boekaerts M, Kroonenberg PM. The stress and coping questionnaire for children (school version and asthma version): construction, factor structure, and psychometric properties. Psychol Rep. 2002; 91:29-36. [PubMed: 12353795]

Rodrigues SM, LeDoux JE, Sapolsky RM. The influence of stress hormones on fear circuitry. Annual review of neuroscience. 2009; 32:289-313.

Rogosa D, Brandt D, Zimowski M. A growth curve approach to the measurement of change. Psychological bulletin. 1982; 92:726-748.

Romeo RD, McEwen BS. Stress and the adolescent brain. Ann N Y Acad Sci. 2006; 1094:202-214. [PubMed: 17347352]

Saigh PA, Yasik AE, Oberfield RA, Halamandaris PV, Bremner JD. The intellectual performance of traumatized children and adolescents with or without posttraumatic stress disorder. Journal of abnormal psychology. 2006; 115:332-340. [PubMed: 16737397]

Seeley WW, Menon V, Schatzberg AF, Keller J, Glover GH, Kenna H, Reiss AL, Greicius MD. Dissociable intrinsic connectivity networks for salience processing and executive control. The Journal of neuroscience : the official journal of the Society for Neuroscience. 2007; 27:2349-2356. [PubMed: 17329432]

Shalev I, Entringer S, Wadhwa PD, Wolkowitz OM, Puterman E, Lin J, Epel ES. Stress and telomere biology: a lifespan perspective. Psychoneuroendocrinology. 2013; 38:1835-1842. [PubMed: 23639252]

Shaw P, Kabani NJ, Lerch JP, Eckstrand K, Lenroot R, Gogtay N, Greenstein D, Clasen L, Evans A, Rapoport JL, Giedd JN, Wise SP. Neurodevelopmental trajectories of the human cerebral cortex. The Journal of neuroscience : the official journal of the Society for Neuroscience. 2008; 28:35863594. [PubMed: 18385317]

Shea A, Walsh C, Macmillan H, Steiner M. Child maltreatment and HPA axis dysregulation: relationship to major depressive disorder and post traumatic stress disorder in females. Psychoneuroendocrinology. 2005; 30:162-178. [PubMed: 15471614]

Sheridan MA, Fox NA, Zeanah CH, McLaughlin KA, Nelson CA 3rd. Variation in neural development as a result of exposure to institutionalization early in childhood. Proceedings of the National Academy of Sciences of the United States of America. 2012; 109:12927-12932. [PubMed: 22826224]

Sheridan MA, McLaughlin KA. Dimensions of early experience and neural development: deprivation and threat. Trends in cognitive sciences. 2014; 18:580-585. [PubMed: 25305194] 
Simmonds DJ, Hallquist MN, Asato M, Luna B. Developmental stages and sex differences of white matter and behavioral development through adolescence: a longitudinal diffusion tensor imaging (DTI) study. Neuroimage. 2014; 92:356-368. [PubMed: 24384150]

Sowell ER, Peterson BS, Thompson PM, Welcome SE, Henkenius AL, Toga AW. Mapping cortical change across the human life span. Nat Neurosci. 2003; 6:309-315. [PubMed: 12548289]

Sowell ER, Thompson PM, Tessner KD, Toga AW. Mapping continued brain growth and gray matter density reduction in dorsal frontal cortex: Inverse relationships during postadolescent brain maturation. J Neurosci. 2001; 21:8819-8829. [PubMed: 11698594]

Stein DJ, Chiu WT, Hwang I, Kessler RC, Sampson N, Alonso J, Borges G, Bromet E, Bruffaerts R, de Girolamo G, Florescu S, Gureje O, He Y, Kovess-Masfety V, Levinson D, Matschinger H, Mneimneh Z, Nakamura Y, Ormel J, Posada-Villa J, Sagar R, Scott KM, Tomov T, Viana MC, Williams DR, Nock MK. Cross-national analysis of the associations between traumatic events and suicidal behavior: findings from the WHO World Mental Health Surveys. PloS one. 2010; 5:e10574. [PubMed: 20485530]

Stevens MC, Pearlson GD, Calhoun VD. Changes in the interaction of resting-state neural networks from adolescence to adulthood. Hum Brain Mapp. 2009; 30:2356-2366. [PubMed: 19172655]

Supekar K, Musen M, Menon V. Development of large-scale functional brain networks in children. PLoS biology. 2009; 7:e1000157. [PubMed: 19621066]

Tam SY, Houlihan S, Melendez-Torres GJ. A Systematic Review of Longitudinal Risk and Protective Factors and Correlates for Posttraumatic Stress and Its Natural History in Forcibly Displaced Children. Trauma, violence \& abuse. 2015

Thomason ME, Foland LC, Glover GH. Calibration of BOLD fMRI using breath holding reduces group variance during a cognitive task. Hum Brain Mapp. 2007; 28:59-68. [PubMed: 16671081]

Thomason ME, Hamilton JP, Gotlib IH. Stress-induced activation of the HPA axis predicts connectivity between subgenual cingulate and salience network during rest in adolescents. $\mathrm{J}$ Child Psychol Psychiatry. 2011; 52:1026-1034. [PubMed: 21644985]

Thomason ME, Marusak HA, Tocco MA, Vila AM, McGarragle O, Rosenberg DR. Altered amygdala connectivity in urban youth exposed to trauma. Soc Cogn Affect Neurosci. 2015

Thomson R, Holland J. Hindsight, foresight and insight: the challenges of longitudinal qualitative research. International Journal of Social Research Methodology. 2003; 6:233-244.

Tottenham N. Human amygdala development in the absence of species-expected caregiving. Developmental psychobiology. 2012; 54:598-611. [PubMed: 22714586]

Tottenham N. The importance of early experiences for neuro-affective development. Current topics in behavioral neurosciences. 2014; 16:109-129. [PubMed: 24264369]

Tottenham N, Hare TA, Quinn BT, McCarry TW, Nurse M, Gilhooly T, Millner A, Galvan A, Davidson MC, Eigsti IM, Thomas KM, Freed PJ, Booma ES, Gunnar MR, Altemus M, Aronson J, Casey BJ. Prolonged institutional rearing is associated with atypically large amygdala volume and difficulties in emotion regulation. Developmental science. 2010; 13:46-61. [PubMed: 20121862]

Tottenham N, Sheridan MA. A review of adversity, the amygdala and the hippocampus: a consideration of developmental timing. Frontiers in human neuroscience. 2009; 3:68. [PubMed: 20161700]

Turkeltaub PE, Eden GF, Jones KM, Zeffiro TA. Meta-analysis of the functional neuroanatomy of single-word reading: method and validation. Neuroimage. 2002; 16:765-780. [PubMed: 12169260]

Uddin LQ. Salience processing and insular cortical function and dysfunction. Nature reviews Neuroscience. 2015; 16:55-61.

van der Werff SJ, Pannekoek JN, Veer IM, van Tol MJ, Aleman A, Veltman DJ, Zitman FG, Rombouts SA, Elzinga BM, van der Wee NJ. Resting-state functional connectivity in adults with childhood emotional maltreatment. Psychol Med. 2012:1-12.

Van Essen DC, Ugurbil K, Auerbach E, Barch D, Behrens TE, Bucholz R, Chang A, Chen L, Corbetta M, Curtiss SW, Della Penna S, Feinberg D, Glasser MF, Harel N, Heath AC, Larson-Prior L, Marcus D, Michalareas G, Moeller S, Oostenveld R, Petersen SE, Prior F, Schlaggar BL, Smith 
SM, Snyder AZ, Xu J, Yacoub E. The Human Connectome Project: a data acquisition perspective. NeuroImage. 2012; 62:2222-2231. [PubMed: 22366334]

Vyas A, Mitra R, Shankaranarayana Rao BS, Chattarji S. Chronic stress induces contrasting patterns of dendritic remodeling in hippocampal and amygdaloid neurons. J Neurosci. 2002; 22:6810-6818. [PubMed: 12151561]

Wang L, Dai Z, Peng H, Tan L, Ding Y, He Z, Zhang Y, Xia M, Li Z, Li W, Cai Y, Lu S, Liao M, Zhang L, Wu W, He Y, Li L. Overlapping and segregated resting-state functional connectivity in patients with major depressive disorder with and without childhood neglect. Human brain mapping. 2013

Woon FL, Hedges DW. Hippocampal and amygdala volumes in children and adults with childhood maltreatment-related posttraumatic stress disorder: a meta-analysis. Hippocampus. 2008; 18:729736. [PubMed: 18446827]

Woon FL, Sood S, Hedges DW. Hippocampal volume deficits associated with exposure to psychological trauma and posttraumatic stress disorder in adults: a meta-analysis. Progress in neuro-psychopharmacology \& biological psychiatry. 2010; 34:1181-1188. [PubMed: 20600466]

Young LD, Suomi SS, Harlow HF, McKinney WT Jr. Early stress and later response to separation in rhesus monkeys. The American journal of psychiatry. 1973; 130:400-405. [PubMed: 4632388]

Zlotnick C, Mattia J, Zimmerman M. Clinical features of survivors of sexual abuse with major depression. Child abuse \& neglect. 2001; 25:357-367. [PubMed: 11414395] 


\section{Highlights}

- $\quad$ Early trauma is associated with altered function in neural pathways of the developing brain

- Longitudinal research is needed to dissect individual trajectories of risk and resilience following trauma

- $\quad$ Separable forms of trauma impact unique neural pathways

- $\quad$ Chronic stress may confound studies of trauma, but is also ecologically valid as representative of typical conditions

- Understanding of trauma within an integrated brain context will aid discovery 

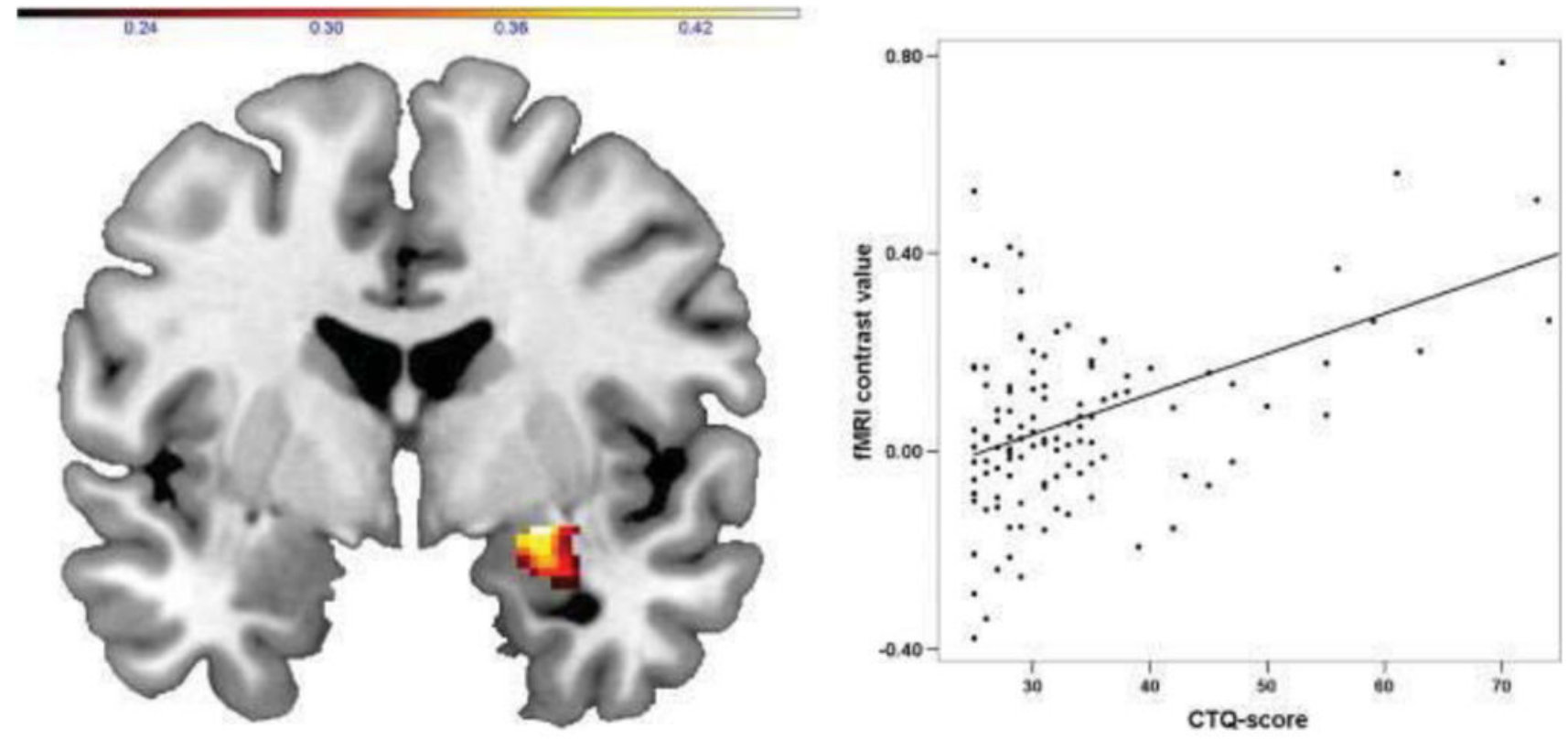

Figure 1.

Neurobiological correlates of childhood trauma are evident even decades later into adulthood. History of childhood maltreatment is positively associated with amygdala responses to negative facial expressions in adults (Dannlowski et al., 2012). Copyright: Elsevier, reprinted with permission. 

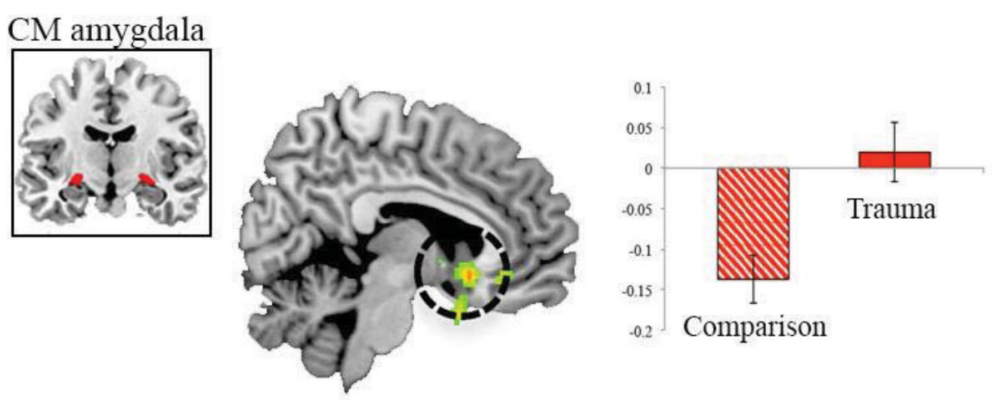

Figure 2.

Lack of negative centromedial (CM) amygdala-subgenual anterior cingulate cortex restingstate functional connectivity in trauma-exposed youth. Urban children and adolescents (ages $9-15)$ with a history of trauma $(n=21)$ compared to their unexposed counterparts. Results shown at $p<0.005$ cluster minimum $=10$ voxels. Error bars represent standard error. From (Thomason et al., 2015). 


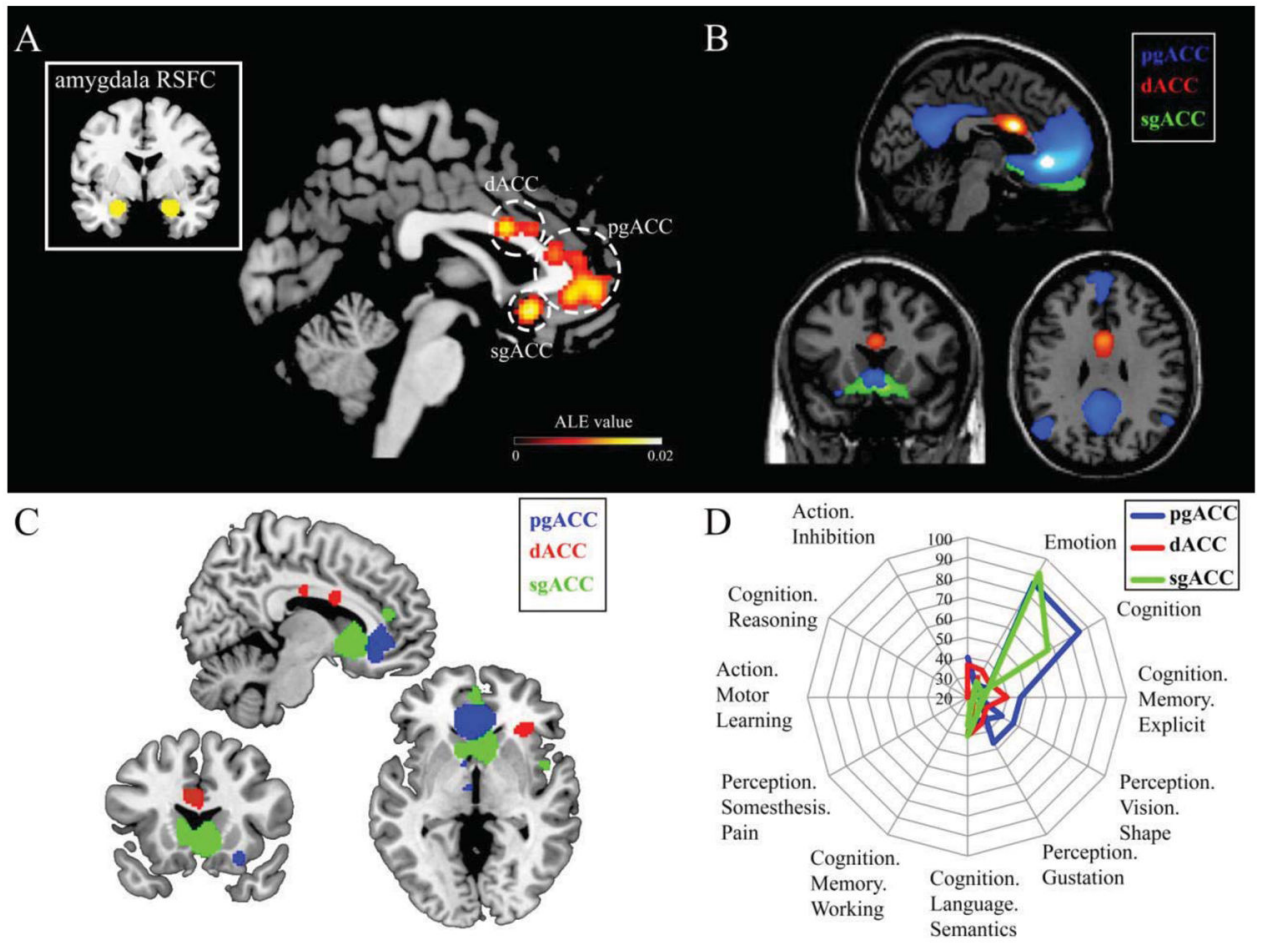

Figure 3. Regional substructure of the $\mathrm{mPFC} / \mathrm{ACC}$

Panel A, meta-analysis of 29 resting-state studies linking psychopathology risk/ symptomology to differences in amygdala to mPFC/ACC connectivity yielded 3 distinct peak clusters. Panel B, supporting the notion that these constitute unique circuits, mPFC/ACC peaks show unique patterns of whole-brain resting-state functional connectivity. Resting-state functional connectivity used publicly available data at Neurosynth.org in $\mathrm{N}=$ 1000 healthy adults at $\mathrm{p}<0.01$ FDR-corrected threshold. Panel C, data-derived mPFC/ACC subareas show unique patterns of co-activation during tasks. This was determined using meta-analytic connectivity modeling (Eickhoff et al., 2011) via GingerALE and the BrainMap.org database (accessed on 7/9/15) thresholded with cluster-level FWE-corrected $p$ $<0.05$ and voxel level $\mathrm{p}<0.001$. Panel D, radar plots depicting number of experiments contributing to panel $\mathrm{C}$ effects organized by behavioral domains. All domains with $\geq 20$ corresponding studies are included. All images displayed on standard templates.

Abbreviations: anterior cingulate cortex, ACC, pregenual ACC, pgACC, dorsal ACC, dACC, subgenual ACC, sgACC, activation likelihood estimation, ALE; family-wise error, FWE; false discovery rate, FDR. 